\title{
An Inexpensive Transaction Number Charging System With Book Record
}

$\mathrm{M}$

OST OF THE MECHANIZED charging systems fail to meet the requirements of university, college, and certain other libraries. These libraries need a record of charged out books arranged by call number. The system proposed here is designed to meet this need specifically and to bring about operational savings at the same time. It is of special interest to libraries that are contemplating extensive reclassification, because book pockets and book cards have been eliminated. Libraries with crowded charging desks will welcome the separation of the book discharge procedure from the desk.

The components of the proposed system are not new. Transaction numbers have been used for charging with success in many libraries; and marginal punched cards, used lately in libraries, have been employed in business establishments for such a long time that the patent rights have expired. The proposed system is very flexible, but there is no need to point out the many possible variations in order to show more clearly the one modification of most general application. Libraries with circulation figures of less than 100 per day may prefer to dispense with the punching of the transaction number in charging, then hand-sort the charge cards in the final discharging procedure.

One feature of the proposed system is the availability of the charge cards for analysis of book circulation without interference to the regular circulation rou-

$M r$. Rift is serials cataloger, University of Missouri Library. tines. Overdues and renewals require a small amount of extra work; but the adoption of the system is urged on the premise that this extra work is well compensated by work savings on regular charges, which are greatly in the majority.

As is generally true, a full description of an unfamiliar system appears much more complicated than the system would be in operation. In our description, we shall follow the processes connected with a book, just cataloged, through the preparation, charging and discharging procedure; then we shall examine how the system works; and finally we shall compare it, working step by working step, with the book-card/date-due tab system, the twobook-cards system, and the call slip used as charge card (closed-stack library) system.

\section{Preparation, Charging, and Discharging of a Book}

The book has just been cataloged and both a designated page and the spine have been marked with the call number. A date-due slip is pasted into the book and it is ready for shelving. No book pocket or book card is needed.

When the patron wants to take the book out, he is required to fill out a charge card essentially like the one illustrated. These cards should be freely available to the partons for use at the catalog. In closed stack libraries they would serve also as call slips.

At the charging desk we find a numbering machine like the ones used in many libraries for accessioning. The machine is set to stamp the same number twice be- 
fore it advances one number. Coupled with this numbering machine is a date stamp, which is set to indicate the date due. The desk attendant stamps the datedue slip and the charge card with that double stamping machine, so that both the slip and the card show the same identical number and date due. Henceforth, we shall refer to the number stamped by the numbering machine as the transaction number.

As soon as the date-due slip has been stamped, the patron can leave the desk with the book.

The desk attendant punches the charge card, a simple procedure requiring detailed explanation. Let us first consider the date-due code shown at the top of the charge card. The code refers to one calendar month and we see that there are ten numbers available for each month. Therefore, one might assign number (1) for books due on the first, second, and third of the month, number (2) for books due the fourth, fifth, and sixth of the month, and so on. (Of course each code number could be used to indicate a longer span of days, if desirable.)

Our punch is very similar to a threehole punch used in most offices, but it punches out in a scallop pattern all numbers except the one which we are coding. A charge card for a book due January 5 would look like the illustration of a charge card coded for date due.

All this punching can be done with the movement of one lever, just as on a three-hole punch. The punch must be reset whenever the date-due code changes.

On the right-hand side of the charge card we see the code for the transaction number. This type of code is the standard sequence sorting code adopted for marginal punched cards. Again, we use a punching machine similar to a three-hole punch, but instead of one lever punching three holes, we have a punch key for each number shown on the card, each key

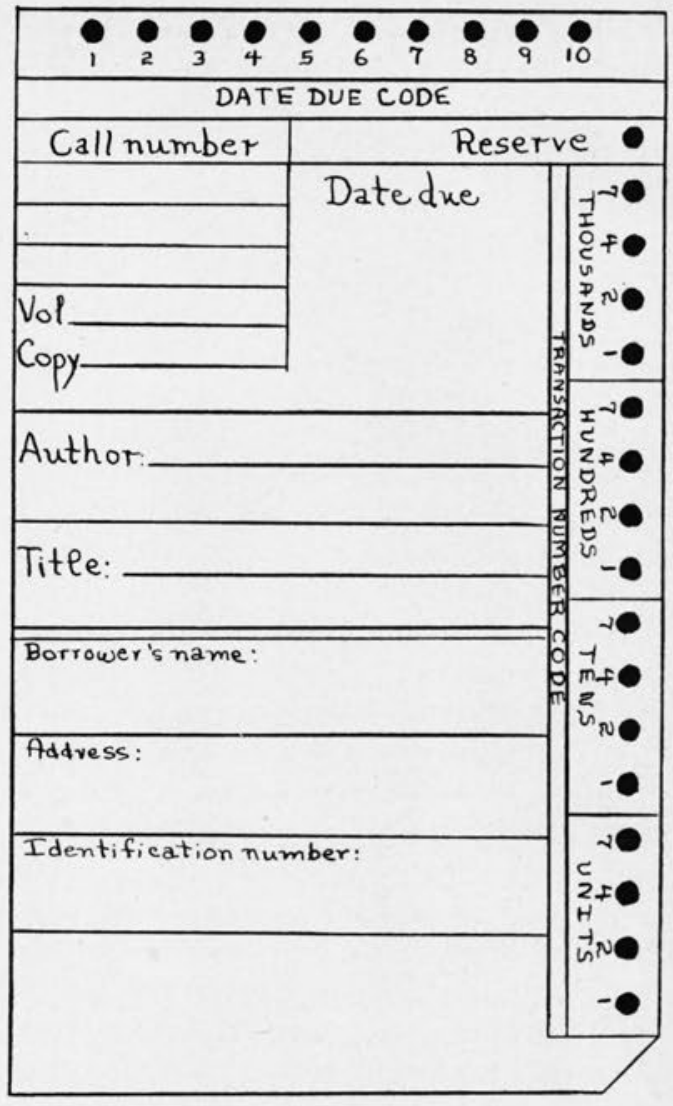

Charge Card

marked like the number keys of a typewriter or adding machine. Each key punches out a groove at the spot designated by the corresponding number on the card.

To punch the transaction number 376 into the charge card, the attendant inserts the card and presses the following keys: 100, 200, 70, 2, and 4. The right hand margin of the card then looks like the accompanying illustration.

After a little practice on the transac-

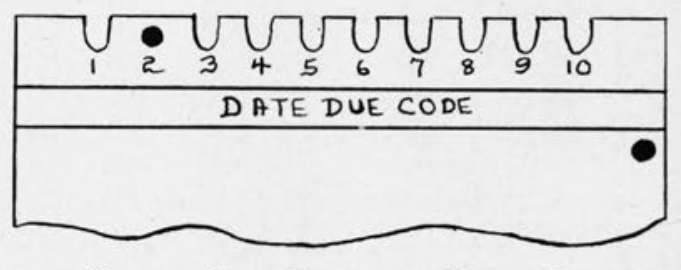

Charge Card Coded for Date Due 


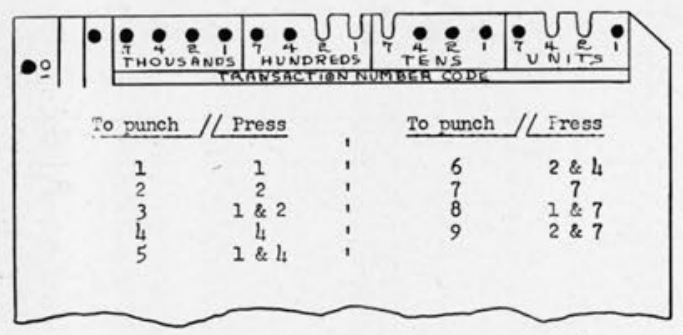

Charge Card Coded for Transaction Number

tion number punch, the attendant will be able to press two keys simultaneously, so that the whole punching process may be accomplished in approximately ten to twelve seconds per card. ${ }^{1}$

The card is then filed by book number in the circulation file (book record) and normally remains there till the last coded due date-in our case till the night of January 6 , because date-due code number 2 covers the period of January 4, 5, and 6 .

We will come back to our charge card later on after discussing the first step in the discharge procedure and the use of mimeographed or printed check lists. The lists represent transaction numbers arranged in columns, headed by the datedue code number, starting with number one and ending with the maximum number circulation expected during the time that one date-due code is effective-in our case, the maximum circulation expected during three days.

When the book is returned, the transaction number on the date-due slip and the corresponding number on the check list are both crossed off the check list. The book is immediately ready for shelving.

As mentioned, the card for date-due code number 2, January, 1953, transaction number 376 , remains in the circulation file till the night of January 6 . On the following day, a clerk or desk attendant takes a key for marginal punched cards, which resembles a knitting needle

\footnotetext{
${ }^{1}$ Charge cards could be bought pre-numbered and pre-punched and kept at the charge desk. The borrower would fill out a paper sticker which would then be pasted to the card. If this version appears preferable, the author will gladly supply further information.
}

with a handle. He inserts the key through the number 2 date-due code holes of the cards in each file tray and lifts out the cards so coded with one movement for each tray. That action ends the discharging procedure for our particular book, provided it has been returned on time and does not represent a special charge. Problems of that nature will be discussed at the end of the following section.

\section{How the System Works}

Any charging system must be designed to perform a particular job at the lowest possible cost of operation. Practically all circulation records indicate which books are charged out to whom and when they are due. In our case, this information must be filed by call number, so that a person inquiring about a particular book can be told whether the book is out, who has it, and when it is due.

The charging and discharging procedures of the proposed system have been explained in detail, and it remains to compare them with the routines of the now prevalent systems using book cards ${ }^{2}$ and/or call slips. Such a comparison shows that libraries using book cards will save considerable working time by eliminating book cards and book pockets, but the patron has more writing to do on the charge cards, especially when he selects books directly from the shelves. (Patrons who check out many books may prefer to have a rubber stamp made with name, address, and identification number and then carry stamped cards.) When charging books, the desk attendant must check the call number on the charge card with the one on the book. Although this procedure takes some time, it takes little longer than charging with a book card. Book cards also must be checked, because they are often placed in the wrong book and mistakes do happen in the typing of new and replacement cards. In

2 Book cards are cards bearing the author, title, and book number of a book and are placed inside that book while it is on the shelves. 
closed stack libraries that use call slips for their charge files, the charge card would also serve as call slip and the savings in adopting the proposed system would be derived entirely from the simplified discharge procedure. The punching of the charge card takes little more time than any other means of indicating the date due. ${ }^{3}$

When the book is returned, only the transaction numbers are crossed off on the check list and on the date-due slip. How does that procedure affect our circulation routine? In the first place, the book need not be returned to the charging desk or circulation file for discharging. The book can be handled in an adjacent room, by a person who need not know anything about book numbers and the circulation file. Because the crossing off of the transaction numbers takes only a few seconds, the book is immediately ready for shelving and there will be fewer inquiries when books are on the shelf instead of being held for discharging with a book card. The books do not physically interfere with access to the circulation file nor does the discharging procedure interfere with the desk attendant's access to the circulation file for filing of new cards and for answering inquiries. ${ }^{4}$

The circulation file (book record) contains a card for each book charged out, including those books which have been returned before the coded date due. Because it does contain charge cards for returned books, use of a check list becomes necessary. To determine the location of a book, the desk attendant looks in the circulation file with the following results: (1) If no card is found, the book is in the library. (2) If a card is found, the desk attendant looks at the transaction number and date-due code, then he looks under that number on the check

${ }^{3}$ If the library does not send overdue notices, it must have some other method of claiming the book.

A modification permits the complete physical separation of book return and charge desk. list. (3) If the transaction number on the check list is crossed off, the book has been returned and the attendant discards the charge card. (4) If the transaction number on the check list is not crossed off, the book is still out.

If a book is charged out again before the former charge card has been removed from the circulation file, the attendant filing the new charge card will find call number and copy number duplicated and he can discard the old card.

Renewals are made simply by penciling a red " $\mathrm{R}$ " next to the corresponding transaction number on the check list. Discharge of overdues and renewals and handling of long time charges are discussed later.

We have pointed out that the final discharge procedure for most books consists of pulling the charge cards from the circulation file by means of a key for marginal punched cards. But the pulled cards contain also the overdues and renewals. To find them, we sort the cards in sequence of transaction number by means of the punched transaction number code. This is not the place to explain how the code works; any firm trading in marginal punched cards will gladly arrange for a demonstration. At this time it may suffice to say that the cards are aligned, then the key is inserted subsequently into every code groove (or hole) from right to left. Each time, part of the cards will drop out and the dropped cards are placed at the back of the pack being sorted. This system is the fastest card sequence sorting system presently used in American business establishments. The whole procedure takes only a few minutes for each time the cards are pulled from the circulation file.

Now we take the check list and pick out the charge card for every transaction number not crossed off. The rest of the cards are discarded. Cards for books which have been renewed, as indicated on the check list, are marked with an 
"R." If desirable, overdue notices are sent out for the overdue books. Then a signal tab is placed on the upper lefthand margin of each card and the cards are put back into the circulation file.

Overdue and renewed books must be returned to the circulation desk for individual pulling of the charge card. These cards can be found easily because they are marked with tabs. Charge cards for overdue books will be pulled automatically once a month for further action. They can be recognized among the pulled cards by the signal tab and should be taken out before the sequence sorting of the cards.

Charge cards for long-time charges will have all date-due numbers punched out and therefore are not affected by the sorting key when pulling cards due. These books must be returned to the circulation file for individual pulling of the charge cards. If whole collections are checked out and returned in one group, as is often the case in libraries with reserve rooms, then a special code can be punched. Such a code provision is shown in the illustration of the charge card marked "Reserve." Additional special coding could be provided on the bottom and left-hand margin of the card for charges and circulation analysis. To drop out cards so coded, all cards must be removed from the circulation file in groups and the key inserted at the special code groove. The cards that remain on the key retain their proper order and can simply be placed back in the circulation file. The same method could be used to take inventory of a special collection checked out.

\section{Comparison of Working Steps}

\section{SYSTEM A \\ Single book card/date-due tab system \\ SYSTEM B \\ Two-card system}

(Variations from system A shown in parenthesis)

A book pocket is pasted into each book.

A book card is typed and placed in the book pocket of every book, including hundreds that will never be used. ( 2 cards)

A date-due slip is pasted into each book.

Not needed

The patron writes his name, number and address on the book card (s).

Desk attendant stamps date due on date-due slip and on the book card (s).

\section{Not needed}

\section{Charging}

\section{SYSTEM C \\ Call slip used as charge card system \\ (in closed stack library)}

I. Preliminary Work

Not needed

Not needed

Same as A

Patron writes same as in $\mathrm{D}$ on call slip.

He stamps same on date-due slip and call slip.

\section{SYSTEM D}

Marginal punch card/transaction number stamp system
Not needed

Not needed

Same as A

Prepare mimeographed checklist. One stencil, 500 copies, supply four years requirements.

The patron writes name, number, address, call no., author, and title on charge card.

Desk attendant stamps transaction number and date due on the datedue slip and on the charge card (all on one stamp). 
Desk attesdant places date-due tab on the book card. (Not for two-card system)

Desk attendant files book card(s) by call number (and date due).

\section{SYSTEM A AND B}

Book is returned to circulation desk for discharging procedure. (Space needed for returned books)

Book card (s) for each individual book is (are) searched for and removed from the circulation file (s) by a person who must understand that file (the files)-Interference with filing of book cards and with consultation of the file. Space needed for a person to search for the cards for returned books.

Book card (s) is (are) placed into book pocket.

Book is ready for shelving.
Same as A or D according to system used.

He files call slip by call number.

\section{Discharging}

Same as A

Same as A

Same as A

Same as A

Same as A

individual book cards from the circulation file on or after date due. Act on overdues. Change tabs. Refile book cards in circulation file. (For two-card system: Write overdues from date-due file.)

Search for book card.

Same as A

Enter new date due on book card. Same as A

Change tabs on book card. (Pull Same as A and refile date-due card.)

\section{SYSTEM C}

\section{Overdues}

Desk attendant punches date due and transaction number code on the charge card.

He files charge card by call number.

SYSTEM D

Book is returned near circulation desk for discharging procedure. (Could be modified to return anywhere in the library.)

The transaction number appearing on the date-due slip in the returned book and the corresponding number on the check list are crossed off. The book is immediately ready for shelving.

Once for each date-due code:

All charge cards for books due are removed from the circulation file by means of the sorting key.

Act on and refile one month overdues. (Cards with tabs)

Charge cards are sequence sorted according to transaction number by means of a sorting key. Transaction numbers not checked off on the check list are overdues or renewals. Mark " $\mathrm{R}$ " on renewal cards. Attach tabs to overdue and renewal cards and refile. Discard balance of cards. NOTE: The marginal punch sequence sorting system is the fastest card sequence sorting system presently used.

Charge cards are automatically pulled on or after date due by means of the sorting key. Remove cards after sequence sorting as explained in discharging procedure. Act on overdues. Refile charge cards in circulation file.

\section{RENEWALS}

Mark transaction number on check list with "R."

Charge card will be pulled out of the circulation file on the original date due.

Mark charge card with " $R$," attach tab and refile in circulation file. 
Search circulation file for book card. Same as A

If no card is found, book is in the Same as A library.

If card is found, book is out.
Same as $\mathbf{A}$
Search circulation file for charge card.

Same as A.

When card is found, check transaction number on check list. If the transaction number is checked off on the list, book has been returned, and the charge card should be discarded. If the number is not checked off, book is still out.

VII. Book Collections Checked Out and Returned in One Parcel

(Reserve room, departments, binding, class room, etc.)

Books must be discharged indi- Same as A vidually.
By use of specially coded cards, the sorting key can be used to discharge the whole collection at once. This method can be used also for taking inventory of books loaned to a special collection.

\section{A Quagmire of Scientific Literature?}

(Continued from page 106)

sive current subject bibliographies are a primary need. Tauber has stated that "it is almost certain that more selective subject catalogs and more extensively used subject bibliographies will characterize subject analysis in the immediate future." ${ }^{15}$ A secondary need is for comprehensive indexing of serial publications, where the situation is distinctly unsatisfactory. Librarians have been ineffectual in eliminating wasteful overlapping of services and in obtaining inclusive indexing; this is a critical situation into which

\footnotetext{
15 Maurice F. Tauber and Associates, Technical Serv ices in Libraries (New York: Columbia University Press, 1954), p. 175.

${ }^{16}$ On the indexing situation, see Verner W. Clapp and Kathrine O. Murra, "The Improvement of Bibliographic Organization," Library Quarterly, XXV (1955), 107.
}

must be put much more effort. ${ }^{16}$ It is $\log$ ical to expect that a great increase in extremely brief subject entries, arranged in chronological order, will characterize the future subject indexes to scientific materials - with the older material being indexed merely by an author file, and with subject cards thrown out after a period of time.

It can be said with complete assurance that scientific libraries have somewhat different problems from libraries in other disciplines, that they are still far from having satisfactory bibliographical control over scientific literature, and that existing library methods if fully exploited can bring firm ground out of the quagmire that now seems to be threatening. 